\title{
APPLICATION OF A RATE DEPENDENT MODEL ON A UD NCF CARBON/EPOXY COMPOSITE
}

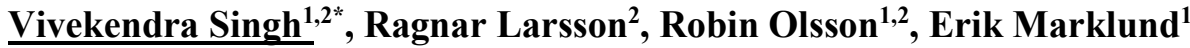 \\ ${ }^{1}$ Polymeric materials and Composites, RISE Research Institutes of Sweden, Mölndal, Sweden \\ ${ }^{2}$ Industrial and Material Science, Chalmers University of Technology, Göteborg, Sweden \\ * vivekendra.singh@ri.se
}

To support the modelling of composites under rapid transient loading, e.g. impact, crash, and vibrations, a computational multiscale constitutive model has been developed for the progressive failure of unidirectional carbon fibre composites. The model is computationally efficient and captures anticipated failure modes to an acceptable accuracy. Computational homogenization and micromechanics are utilized in the modelling at the ply scale. A major focus is to predict the strain rate dependent nonlinear constitutive behaviour of unidirectional composite plies [1]. The fibres are assumed transversely isotropic, whereas the polymer is viscoelastic-viscoplastic, including a pressure dependent strength. Degradation of the polymer matrix is described by a recently developed continuum damage mechanics approach [2]. The model has been successfully implemented as a VUMAT subroutine in Abaqus/Explicit. Figure 1 shows FE simulation of strain localization as compared to experimental results of IM7/8552 in dynamic off-axis compression [3]. Reasonable correlation was found between the measured and numerically predicted results.

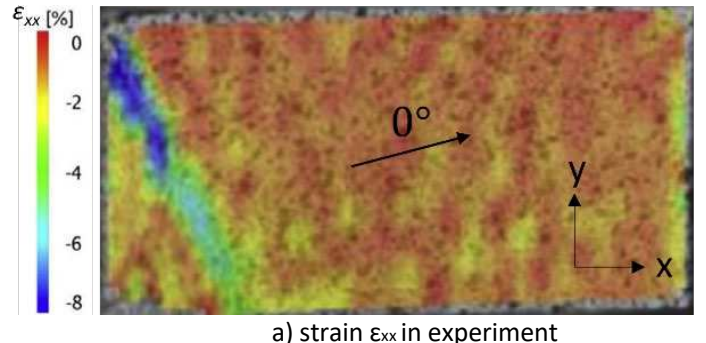

Figure 1. Measured and predicted dynamic failure of $15^{\circ}$ off-axis specimen in compression. Experiments are from Koerber et al. [3].

In the present paper the model is applied to simulate quasi-static and dynamic off-axis tension and compression experiments on composite coupons studied in two of our collaborative projects. The composite is a unidirectional (UD) carbon fibre non-crimp fabric (NCF) uniweave impregnated with LY556 epoxy, manufactured by Resin Transfer Moulding (RTM). The tests have been performed using a high-speed hydraulic test machine and a Split Hopkinson Bar (SHB) setup, involving strain rates of up to about $140 / \mathrm{s}$ in tension and $1100 / \mathrm{s}$ in compression.

\section{References}

[1] R. Larsson, V. Singh, R. Olsson, E. Marklund (2020) A micromechanically based model for strain rate effects in unidirectional composites. Mechanics of Materials, 148, 193-212.

[2] R. Larsson, V. Singh, R. Olsson, E. Marklund (2021) A micromechanically based model for dynamic damage evolution in unidirectional composites, Submitted.

[3] H. Koerber, J. Xavier, P.P. Camanho (2010) High strain rate characterisation of unidirectional carbon-epoxy IM7-8552 in transverse compression and in-plane shear using digital image correlation. Mechanics of Materials, 42, 1004-1019. 